\title{
Prevalence of obstructive urolithiasis in domestic animals: An interplay between seasonal predisposition and dietary imbalance
}

\author{
K. Sharun ${ }^{1}$, K.M. Manjusha ${ }^{1}$, R. Kumar ${ }^{1}$, A.M. Pawde', Y.P. Malik ${ }^{2}$, P. Kinjavdekar ${ }^{1}$, S.K. Maiti ${ }^{1}$ and \\ Amarpal $^{1}$
}

${ }^{1}$ Division of Surgery, ${ }^{2}$ Agricultural Research Information Systems (ARIS) Cell, ICAR-Indian Veterinary Research Institute, Izatnagar, Bareilly, 243122, Uttar Pradesh, India

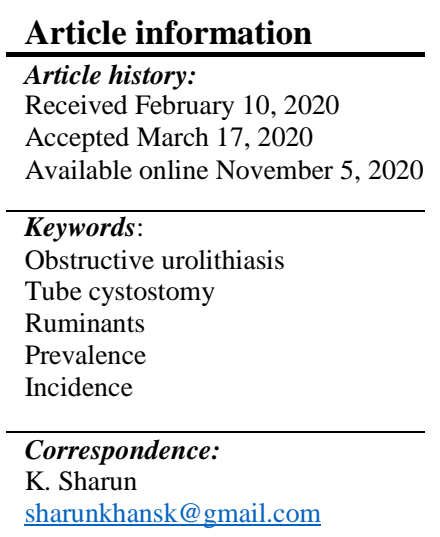

\begin{abstract}
The present study was aimed to record and analyze the prevalence of obstructive urolithiasis in domestic animals like cattle, buffalo, horse, goat, sheep, dog and cat presented at RVP-TVCC, Indian Veterinary Research Institute. A total of 777 cases were reported during the academic session starting from April 2018 to March 2019 from Bareilly and its surrounding regions. Incidence were highest among ruminants $92.92 \%$ comparing to other domestic animals $7.08 \%$. Among the different animal species, caprine were found to be the most affected, followed by buffalo and canine. A positive correlation was noted between the occurrence of obstructive urolithiasis and the season with maximum number of cases being reported during the winter season December - February. The female to male ratios in urolithiasis affected animals were 1:81, 1:75 and 1:22 for buffalo, goat, and dog, respectively indicating higher occurrence in male animals. Majority of the goat $67.89 \%$ and buffalo $84.80 \%$ presented with obstructive urolithiasis were also found to be fed exclusively with a grain rich diet that are excess in phosphorous thereby contributing to urolith formation. The role played by behavioral changes associated with different seasons and the dietary status of the animal plays a significant role in the pathophysiology of urolithiasis. Such an interplay between the season and the dietary imbalance will lead to higher incidence of obstructive urolithiasis in domestic animals.
\end{abstract}

DOI: $10.33899 /$ ijvs.2020.126662.1358, (C2021, College of Veterinary Medicine, University of Mosul.

This is an open access article under the CC BY 4.0 license (http://creativecommons.org/licenses/by/4.0/).

\section{Introduction}

Obstructive urolithiasis in domestic animals is an emergency conditions that have multifactorial etiologies. It has solely transformed into a lifestyle disease among the domestic animals. Ruminants reared by farmer community in the rural areas are the most affected ones due to scarcity of health facilities and other resources. Obstructive urolithiasis is one among the main reasons for death in feedlots, and thus produces high economic loss in livestock industry. If not properly diagnosed, this condition is potentially serious and can even cause rupture of bladder, eventually leading to death (1). In ruminants, it is primarily considered as a nutritional disease, whereas in dogs it is primarily associated with urinary tract infection, supersaturation of urinary solutes, altered urine $\mathrm{pH}$ and nutritional factors (2).

The clinical signs in animals with intact and ruptured urinary bladder is different. Intact urinary bladder is associated with clinical signs such as anuria, anorexia, colic, hematuria, respiratory distress, reluctance to walk, prolonged recumbency, sunken eyes, dull and depressed appearance, frequent straining as an attempt to urinate, tail lifting, engorged urethra, twitching of the penis, licking of prepuce, restlessness, rectal prolapse due to continuous straining, and pain on palpation of penis/urethra. However, ruptured urinary bladder is associated with anuria and bilateral distention of the abdomen (3). 
Formation of urinary calculi can occur anywhere in the urinary tract causing retention of urine (4). Site of lodgment of calculi vary between different animal species due to their physiologic peculiarities. Predisposing factors include diet, sex, age, species, breed, water scarcity, mineral and hormonal imbalances, seasonal variations, genetic constitution, persistent urinary tract infections and management errors. Castration at very young age in small ruminants is one of the attributing factors which interrupt the normal development of urogenital system in males. Lower urinary tract is the most common site of obstruction than upper urinary tract in dogs and cats (5). Incidence of the condition is maximum in goats followed by buffalo calves in accordance with similar studies (6). The incidence of urolithiasis in equines is very low compared to other animal species (7).

The present paper describes the prevalence, incidence, seasonal distribution, and management of obstructive urolithiasis in domestic animals like cattle, buffalo, horse, goat, sheep, dog and cat presented at RVP-Teaching Veterinary Clinical Complex (TVCC), Indian Veterinary Research Institute. A brief discussion on the interplay of seasonal predisposition and dietary imbalance in the occurrence of obstructive urolithiasis is also included in the study.

\section{Materials and methods}

\section{Study area and animals}

The study was conducted in domestic animals presented to RVP-TVCC, Indian Veterinary Research Institute, Bareilly (Coordinates - 28 $23^{\prime} 52^{\prime \prime N} \quad 79^{\circ} 25^{\prime} 53^{\prime \prime} \mathrm{E}$ ) that exhibited the classical signs of obstructive urolithiasis like stranguria, dysuria, anuria, hematuria, oliguria, urinary incontinence, urethral pulsation, abdominal pain, and bilateral distension of abdomen. Diagnosis of obstructive urolithiasis was made based on the history, clinical signs, radiographic, and ultrasonography findings. Additional data were collected regarding the feeding management, body condition, water/fodder availability, and current health status at the time of presentation.

\section{Prevalence and incidence study}

Retrospective analysis was performed on the prevalence of obstructive urolithiasis among the domestic animals during the past 20 academic years from 1999 to 2019 (Each year extending from April to March). The monthly incidence of obstructive urolithiasis was also studied from April 2018 to March 2019 (12 months) to study the pattern of seasonal occurrence. The epidemiological parameters such as species and sex were also collected for analysis during this period. The prevalence $(\mathrm{P})$ was calculated based on the given equation (8). The prevalence was calculated by dividing the total number of obstructive urolithiasis cases presented on total population under study that are at risk and then multiplied by 100 .

\section{Treatment}

Depending on the type of obstruction the choice of treatment was selected. Partial obstructions were managed either medically or by performing less invasive technique like retrohydropropulsion. Complete obstruction is considered as an emergency and was managed by performing different surgical techniques. The selection of appropriate surgical technique was based on the animal species, degree of obstruction, site of obstruction and the condition of the animals.

\section{Statistical analysis}

The collected data were analyzed statistically using Statistical Package for the Social Sciences (SPSS software version 20, 2011). Further the data from different groups were subjected to statistical analysis using Chi-square test $\left(\chi^{2}\right)$ at $\mathrm{P}$-value $0.01,0.05$.

\section{Results}

\section{Prevalence rate}

The prevalence of obstructive urolithiasis in domestic animals were calculated for a period of 20 years extending from 1999 to 2019 (Figure 1). The prevalence rate was highest in the academic year 2013-14 and lowest in 2000-01. The pattern of prevalence rate suggests that there is a constant increase in the occurrence of obstructive urolithiasis among different animal species during the past 20 years. The total number of obstructive urolithiasis cases diagnosed also shows a steady increase in the past 20 years. The highest number of cases was diagnosed in the academic year 2015$16 / 794$ and the lowest in 2000-01/61.

\section{PREVALENCE RATE OF OBSTRUCTIVE UROLITHIASIS (1999-2019)}

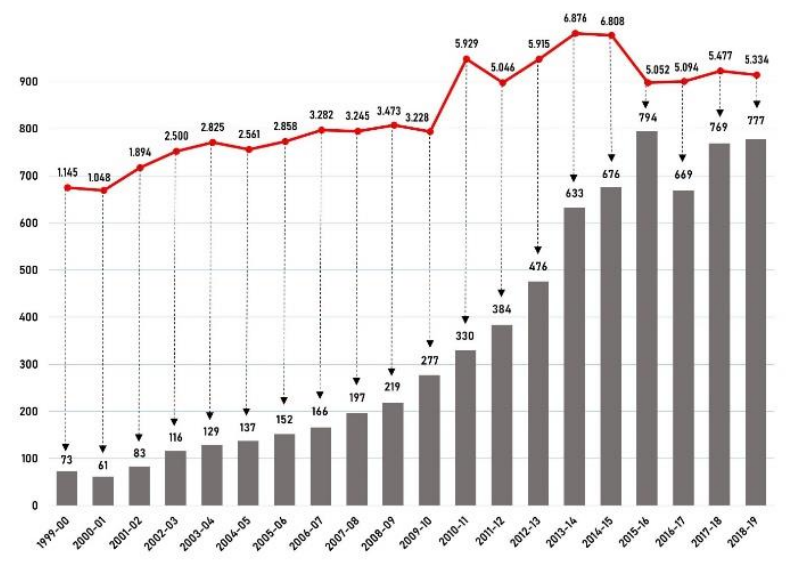

Figure 1: Bar diagram representing the total number of obstructive urolithiasis cases diagnosed in the domestic animals during the past 20 years (1999-2019). The corresponding prevalence rate of each year is given above as a line graph. 


\section{Incidence rate}

The incidence rate of obstructive urolithiasis was noted for a period of one year April 2018 to March 2019 on monthly basis to evaluate species, sex, and seasonal distribution.

\section{Season wise distribution}

Maximum number of obstructive urolithiasis cases was reported during the winter season December, January, and February $-46.20 \%$ and the minimum during the monsoon season June, July, August, and September - 18.40\% (Figure 2 ). The maximum incidence of urolithiasis in domestic animals was found in the month of January $21.36 \%$ followed by February $13.13 \%$ and December $11.71 \%$. Whereas the minimum incidence was reported during the month of August $4.12 \%$.

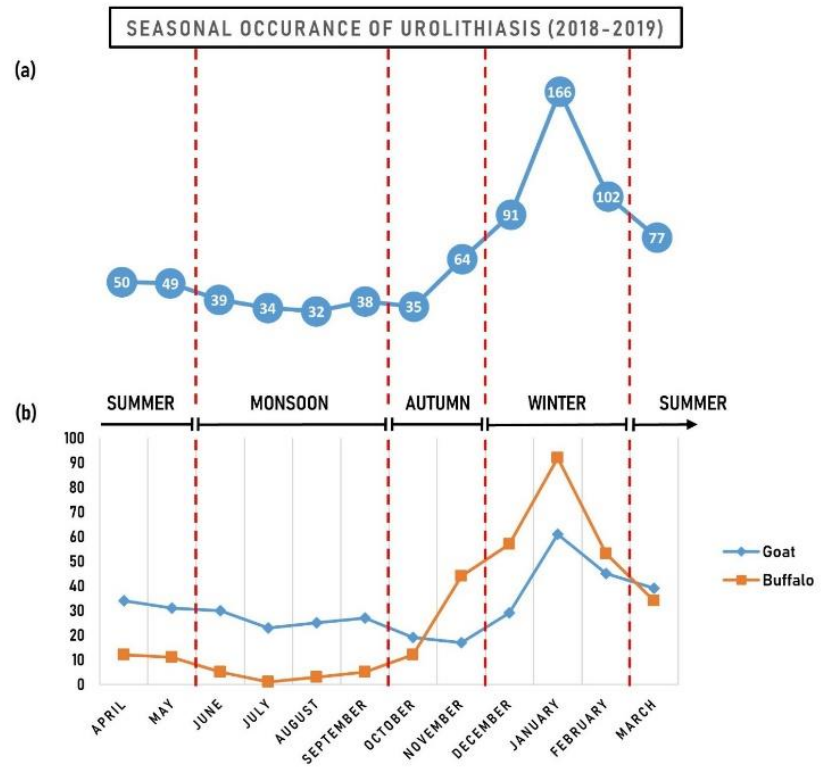

Figure 2: (a) The total number of obstructive urolithiasis cases diagnosed in domestic animals is represented on a monthly basis during the period of April 2018 to March 2019 (12 months). (b) The line graph indicating the total number of cases diagnosed in goat and buffalo. ("Winter season December to February, Pre-monsoon or summer season March to May, Monsoon season - June to September, and Post-monsoon or autumn season - October to November).

\section{Species wise distribution}

The total number of cases diagnosed in individual animal species during the period of April 2018 to March 2019 (12 months) is given in Figure 3. The percentage of occurrence among various species are - goats $48.91 \%$ followed by buffaloes $42.34 \%$ and other animals in the decreasing order sequence as dogs $5.92 \%$, cattle $1.54 \%$, cat $1.03 \%$, sheep $0.13 \%$, and horse $0.13 \%$. The incidence of urolithiasis was found to be highest in the ruminants $92.92 \%$ compared to other domestic animals $7.08 \%$ and was maximum in goats followed by buffalo. Number of cases reported from companion animals like dog and cat was comparatively less $6.95 \%$.

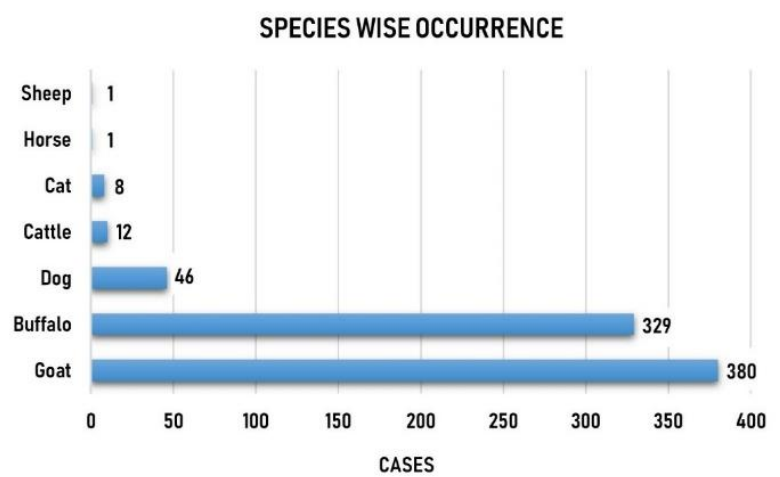

Figure 3: Bar diagram representing the total number of cases diagnosed in individual animal species during the period of April 2018 to March 2019 (12 months).

\section{Sex wise distribution}

The sex wise distribution of obstructive urolithiasis was calculated among the different species. The results were suggestive of higher occurrence in male animals compared to their female counterparts. The female to male ratio among the affected animals were 1:81, 1:75 and 1:22 for buffalo, goat, and dog, respectively (Table 1). Whereas only male animals were found to be affected by obstructive urolithiasis in cattle, horse, sheep, and cat.

Table 1: The female to male sex ratio among the different species is indicative of the higher predisposition of male animals towards the occurrence of obstructive urolithiasis

\begin{tabular}{lccc}
\hline Species & Male & Female & Female : Male \\
\hline Goat & 375 & 5 & $1: 75$ \\
Buffalo & 325 & 4 & $1: 81$ \\
Dog & 44 & 2 & $1: 22$ \\
Cattle & 12 & - & - \\
Cat & 8 & - & - \\
Horse & 1 & - & - \\
Sheep & 1 & - & - \\
\hline
\end{tabular}

\section{Treatment}

The different surgical techniques used for treating obstructive urolithiasis include urethral process amputation (sheep and goat), urethrotomy (cattle), cystotomy (canine and feline), tube cystostomy (sheep, goat, cattle, and buffalo), and ischio-rectal tube cystostomy (cattle) (Figure 4 and 5). Tube cystostomy was considered to be an efficient and economic method for managing obstructive urolithiasis 
in ruminants. Cystotomy was performed mostly in the case of canine and feline patients. Animals presented with cystorrhexis and uroperitoneum were associated with poor prognosis in buffalo and goat.

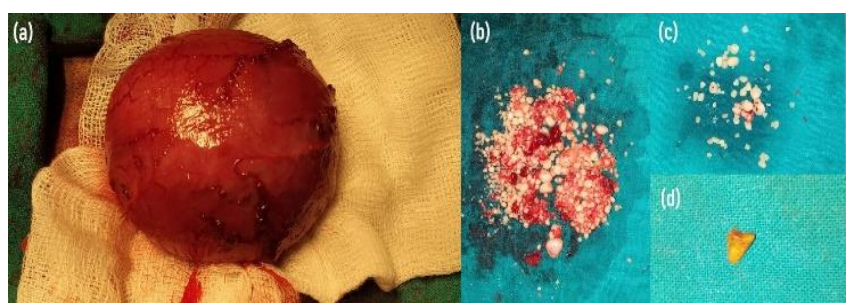

Figure 4: (a) Exteriorized canine bladder containing cystoliths. The bladder wall is thickened and engorged due to obstructive urolithiasis. (b) \& (c) Cystoliths recovered from canine patients. (d) Urolith recovered from the urethra of a bullock by urethrotomy.

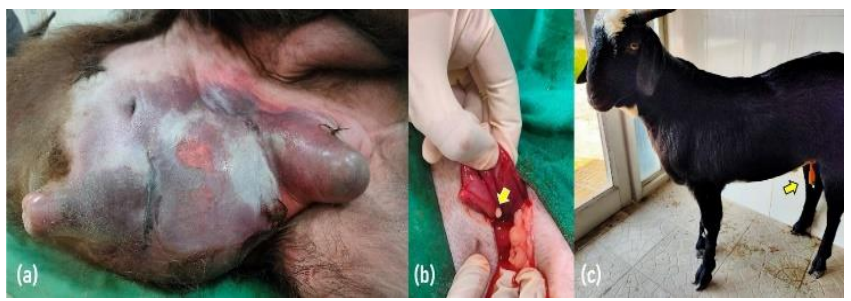

Figure 5: (a) Urine scald associated with urethral rupture, one of the complication of delayed treatment of obstructive urolithiasis. (b) Intraoperative image of urolith (arrow) outside the ruptured bladder. (c) Goat after tube cystostomy.

\section{Dietary imbalance}

Majority of the goat $67.89 \%$ and buffalo $84.80 \%$ presented with obstructive urolithiasis were fed exclusively with a grain diet that is excess in phosphorous and contains very little calcium (Table 2 ). These animals received only very scarce amount of green fodder. The severe scarcity of green fodder in the recent years is the main factor that forces the owners to provide more amount of grains.

Table 2: The feeding status of buffalo and goats that were diagnosed with obstructive urolithiasis during the period of April 2018 to March 2019 (12 months)

\begin{tabular}{lcccc}
\hline Species & \multicolumn{2}{c}{ Type of diet } & \multirow{2}{*}{ Total } & $\begin{array}{c}\text { animals \% fed } \\
\text { grain rich diet }\end{array}$ \\
\cline { 2 - 3 } & grain rich & balanced & & 250 \\
\hline Goat & 258 & 122 & 380 & 67.89 \\
Buffalo & 279 & 50 & 329 & 84.80 \\
\hline
\end{tabular}

$\chi^{2}=27.434$ at a significance level of $1 \%(\mathrm{p}<0.001)$. There is a close association between the feeding practice and the occurrence of obstructive urolithiasis as $p<0.001$, indicating a $p$ value of 0 . This shows that goat and buffalo fed with grain rich diet are more predisposed to obstructive urolithiasis.

\section{Discussion}

Obstructive urolithiasis is a multifactorial disease of animals. Obstruction due to calculi can occur anywhere in the urinary tract and can vary between species. Maximum occurrence is during extreme weather condition of the year can be attributed to reduced water intake and lack of available green fodder leading to Vitamin A deficiency $(6,9)$. The highest occurrence of obstructive urolithiasis were reported during the winter season December, January, and February $-46.20 \%$ and the minimum during the monsoon season June, July, August, and September - 18.40\% indicating a clear cut relationship between the occurrence of urolithiasis and factors like water availability and water intake. During peak winters there can be relative decrease in the water intake by animals, thereby causing super-saturation of urinary solutes, resulting in subsequent precipitation and calculi formation leading to urinary tract obstruction (10). In another study, the incidence rate of urolithiasis was found highest in January $13.93 \%$ and lowest in October $2.57 \%$. The general pattern of occurrence suggests higher prevalence of urolithiasis in between the months of October-February every year (8). The highest occurrence of obstructive urolithiasis observed in our study during the winter season can be the effect of several factors like reduced water intake, scarcity of water supply, and the increased concentrate feeding due to reduced fodder availability. In the monsoon season due to higher availability of rain and the fodder, occurrence of obstructive urolithiasis was found to be significantly low.

The female to male ratio among the affected animal population were 1:81, 1:75 and 1:22 for buffalo, goat, and dog, respectively in this study. The findings were suggestive that the male animals were more susceptible to the occurrence of obstructive urolithiasis compared to their female counterparts. In a similar study, female to male ratio among the animals affected with urolithiasis was found to be $1: 81,1: 56$, and 1:10 among goat, buffalo, and dog respectively (8). Both sexes of animals are prone to obstructive urolithiasis but incidence is much more in males due to the anatomic peculiarities. Obstruction occurs most commonly in the narrowest portions of the urinary tract (11).

Early castration and high grain feeding is the main predisposing factor among goats $(6,12)$. Castration at early age predisposes male animals for obstructive urolithiasis since the hormone testosterone plays an important role in the development of urethra (8). Hence, deficiency of testosterone in young developing animals may affect urethral development resulting in the narrowing of penile urethra. Concentrate diets comprising especially wheat bran predispose the formation of calculi in ruminants. Calcium phosphorus ratio in the diet should be always maintained at an optimum level not less than 1:1 ratio (13). In the present study, a large proportion of animals with obstructive urolithiasis comes under the category of those animals that 
are fed exclusively on grain rich diet (goat $67.89 \%$, buffalo $84.80 \%$ ). Providing concentrate ration that are rich in phosphorus will lead to an imbalance in the calcium and phosphorus ratio. This will create an imbalance in the urinary excretion of calcium and phosphorus. Hence, dietary imbalance is a major contributory factor in the occurrence of urolithiasis in goat and buffalo.

In the present study, incidence of urolithiasis was found to be highest in goats $48.91 \%$ followed by buffaloes $42.34 \%$, dogs $5.92 \%$, cattle $1.54 \%$, cat $1.03 \%$, sheep $0.13 \%$, and horse $0.13 \%$. Goats have the capacity for efficient water utilization and have lower water intake compared to that of sheep (14). This inherent biological mechanism that increases the efficiency of water utilization by reducing the urine output might have played an important role in the higher incidence of obstructive urolithiasis in this species. Among sheep and goats, males are at increased risk compared to females due to their anatomical peculiarity, curvature of the urethra, and the presence of a urethral process that has a narrow diameter in which the calculi get frequently lodged (15). This physiological peculiarity along with the seasonal and dietary factors have contributed greatly to the urolith formation in goats.

Prognosis depends on the stage of presentation and the health status of the animal. Delayed and devastated cases have poor prognosis especially after the onset of uremic symptoms. Uremic symptoms include dullness, depression, rough hair coat, loss of body weight, lethargy, ammoniac odor, impaired renal function, and anemia. Obstructive urolithiasis in domestic animals should be considered as an emergency condition requiring surgical management. Appropriate and timely surgical intervention along with supportive treatments paves the way to favorable prognosis.

\section{Conclusion}

In the present study, Incidence of urolithiasis was found to be highest among the caprine, followed by bubaline and canine species. The prevalence study conducted from the past 20 years data suggest that there is a constant increase in the occurrence of obstructive urolithiasis among different animal species. This increase can be attributed to progressive change in management practices followed in the livestock sector, scarcity of fodder, lack of knowledge regarding balanced diet formulation, and the extreme climatic conditions. There exists a complex relationship between factors like species, sex, breed, water intake, water availability, season, balanced ration, time of castration, management factors and certain physiologic peculiarities that contributes to the occurrence of urolithiasis in domestic animals. Among these factors the role played by behavioral changes associated with seasons and the dietary status of the animal plays a significant role in the pathophysiology of urolithiasis. Such an interplay between the season and the dietary imbalance will lead to higher incidence of obstructive urolithiasis. Therefore, a thorough knowledge on the factors that influence the occurrence of obstructive urolithiasis is required for efficient and cost-effective management.

\section{Conflict of interest}

None of the authors has a financial or personal relationship with other people or organizations that could inappropriately influence or bias the content of the paper.

\section{References}

1. Makhdoomi DM, Gazi MA. Obstructive urolithiasis in ruminants-A review. Vet. World 2013;6(4):233-238. Doi: 10.5455/vetworld.2013.233-238

2. Gazi MA, Khan MA, MakhdoomiI DM, Siraj G, Dar SH, Mir AQ. Possible role of calcium, phosphorous and magnesium shift in blood, urine and calculi in calves affected by urolithiasis. Afr J Agric Res. 2015;10:207-214. Doi: 10.5897/AJAR2014.9126

3. Kushwaha RB, Amarpal HP, Kinjavdekar P, Pawde AM. Clinical appraisal of 48 cases of obstructive urolithiasis in buffalo calves treated with tube cystostomy and urethrotomy. Adv Anim Vet Sci. 2014;2(2):106-110. Doi: 10.14737/journal.aavs/2014/2.2.106.110

4. Singh AK, Gangwar AK, Devil KS. Incidence and management of obstructive urolithiasis in buffalo calves and goats. Adv Anim Vet Sci. 2014;2(9):503-507. Doi: 10.14737/journal.aavs/2014/2.9.503.507

5. Osborne CA, Fletcher TF. Applied anatomy of the urinary system with Clinicopathologic correlation. Philadelphia: Academic Press; 1995. 3$28 \mathrm{p}$.

6. Amarpal, Kinjavdekar P, Aithal HP, Pawde AM, Pratap K and Gugjoo MB A retrospective study on the prevalence of obstructive urolithiasis in domestic animals during a period of 10 years. Adv Anim Vet Sci. 2013;1(3):88-92.

7. Duesterdieck-Zellmer KF. Equine urolithiasis. Vet Clin N Am. 2007;23(3):613-629. Doi: 10.1016/j.cveq.2007.09.003

8. Thakur N, Dey S, Verma M, Jacob A, Choudhary SS, Ge C, Karunanithy M. Epidemiologic evaluation of urolithiasis in Bareilly area of Uttar Pradesh, India. Biol Rhythm Res. 2018;2:1-7. Doi: 10.1080/09291016.2018.1537547

9. Radostits OM, Gay CC, Blood DC, Hinchcliff KW. Veterinary Medicine: A textbook of the diseases of cattle, sheep, pigs, goats and horse. London: Bailliere Tindall; 2000. 1576-1580 p.

10. Parrah JD, Hussain SS, Moulvi BA, Singh M, Athar H. Bovine uroliths analysis: A review of 30 cases. Isr J Vet Med. 2010;65(3):103-107.

11. Ewoldt JM, Jones ML, Miesner MD. Surgery of obstructive urolithiasis in ruminants. Vet Clin N Am. 2008;24(3):455-465. Doi: 10.1016/j.cvfa.2008.06.003

12. Stone WC, Bjorling DE, Trostle SS, Hanson PD, Markel MD. Prepubic urethrostomy for relief of urethral obstruction in a sheep and a goat. J Am Vet Med Assoc. 1997;210(7):939-941.

13. Wang X, Huang K, Gao J, Shen X, Lin C, Zhang G. Chemical composition and microstructure of uroliths and urinary sediment crystals associated with the feeding of high-level cottonseed meal diet to water buffalo calves. Res Vet Sci. 1997;62(3):275-280. Doi: 10.1016/S0034-5288(97)90204-6

14. Farias Machado NA, Filho JA, de Oliveira KP, Parente MD, de Siqueira JC, Pereira AM, Santos AR, Sousa JM, Rocha KS, Viveiros KK, Costa $\mathrm{CD}$. Biological rhythm of goats and sheep in response to heat stress. Biol Rhythm Res. 2019;7:1-9. Doi: 10.1080/09291016.2019.1573459

15. Halland SK, House JK, George LW. Urethroscopy and laser lithotripsy for the diagnosis and treatment of obstructive urolithiasis in goats and pot-bellied pigs. J Am Vet Med Assoc. 2002;220(12):1831-1834. Doi: 10.2460/javma.2002.220.1831 
1 1 ـ Y و آذار 9 ـ ـ من مدينة باريلي و المناطق المحيطة بها. كانت نسبة

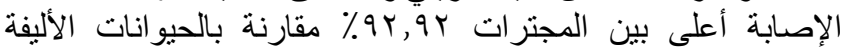

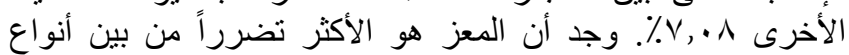

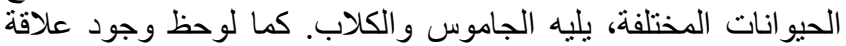

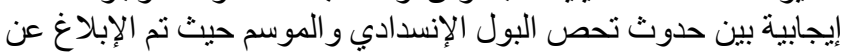

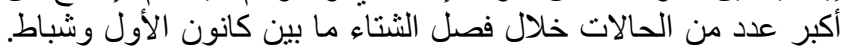

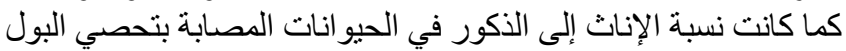

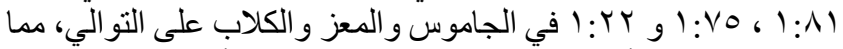

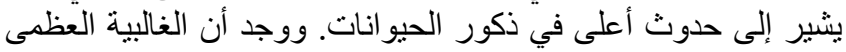

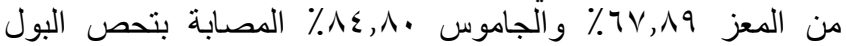

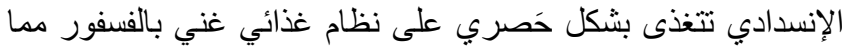

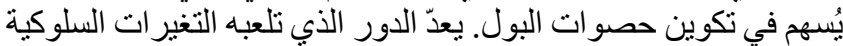

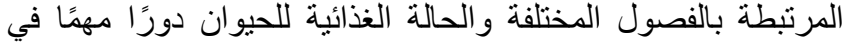

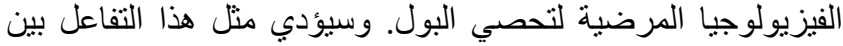

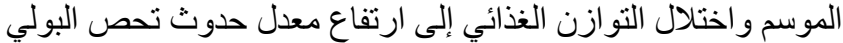
الإنسدادي في الحيو انات الأليفة.
انتشار تحصِّ البول الانسدادي في الحيوانات الأليفة: تفاعل بين الاستعداد الموسمي وعدم التوازن الغذائي

خان شارون'، ك. ك. مانيوشا'، ، روهيت كومار' ، أ.م. باودي'، '، ياثل بال

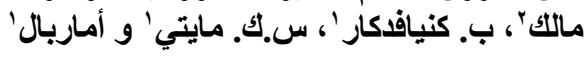

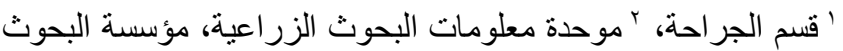

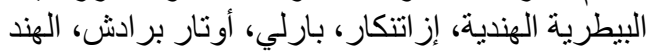

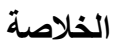

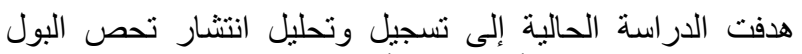

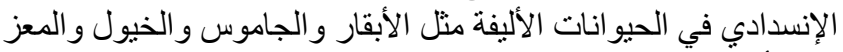

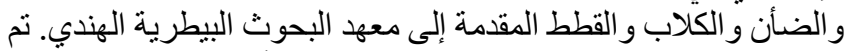
الإبلاغ عن إجمالي حVV حالة خلال الفصل الأكاديمي ما بين نيسان 